\title{
Barreras de entrada en la cadena global de valor de agrobiotecnología en semillas: caso Argentina
}

SANTIAGO CALVO*

Artículo recibido: 25 de septiembre de 2019

Artículo aprobado: 23 de junio de 2020

Doi: https://doi.org/10.12804/revistas.urosario.edu.co/desafios/a.8265

Para citar este artículo: Calvo, S. (2021). Barreras de entrada en la cadena global de valor de agrobiotecnología en semillas: caso Argentina. Desafíos, 33(1), 1-38. https://doi.org/10.12804/ revistas.urosario.edu.co/desafios/a.8265

\section{Resumen}

Las relaciones económicas internacionales asistieron a un complejo proceso de producción de bienes y servicios geográficamente fragmentados y articulados entre sí. Frente a ello, la perspectiva de cadena global de valor destaca el rol predominante de las empresas trasnacionales, así como sus capacidades para restringir la participación de nuevos actores. Entre los paradigmas tecnoproductivos emergentes, se encuentra la biotecnología en semillas. Testigo de una continua concentración empresarial, expresa cabalmente las restricciones impuestas por un reducido grupo de multinacionales. En efecto, el presente trabajo busca explicitar las barreras que enfrentan los actores de Argentina para participar en los eslabones de alto valor agregado a partir de un análisis de la cadena global de valor del sector agrobiotecnológico en semillas.

Palabras clave: cadena global de valor; gobernanza; upgrading; agrobiotecnología en semillas; barreras de entrada.

\footnotetext{
* Universidad Nacional de La Plata. Correo electrónico: lic.santiagocalvo@gmail.com. ORCID: https://orcid.org/0000-0003-4711-8033
} 


\title{
Barriers to Entering the Global Value Chain of Agricultural Biotechnology in Seeds: the Argentine Case
}

\begin{abstract}
This article analyzes the Global Value Chain for agricultural biotechnology in seeds, identiffing the barriers faced by Argentine actors when seeking to participate in high value added stages of the process. Economic international relations have undergone a complex process whereby goods and services are produced in a fragmented manner, yet are articulated among them. In the face of these changes, the Global Value Chain perspective underscores the key role that transnational companies play, including their ability to restrict the participation of new actors. Among the emerging technoproductive paradigms we find seed biotechnology. The area I analyze showcases the restrictions imposed by a few multinational corporations and the continued concentration of businesses.
\end{abstract} Keywords: Global value chain; governance; upgrading; agricultural biotechnology; entry barriers.

\section{Barreiras à entrada na cadeia de valor global da agrobiotecnologia de sementes: o caso da Argentina}

\begin{abstract}
Resumo
As relações econômicas internacionais testemunharam um complexo processo de produção de bens e serviços geograficamente fragmentados e articulados entre si. Diante disso, a perspectiva da cadeia de valor global destaca o papel predominante das empresas transnacionais, bem como sua capacidade em restringir a participação de novos atores. Entre os paradigmas tecnoprodutivos emergentes está a biotecnologia de sementes. Testemunha de uma contínua concentração empresarial, expressa de forma cabal nas restrições impostas por um pequeno grupo de multinacionais. Com efeito, este trabalho busca explicitar as barreiras que os atores argentinos enfrentam para participar de vínculos de alto valor agregado a partir de uma análise da cadeia de valor global do setor agrobiotecnológico de sementes.
\end{abstract}


Palavras-chave: cadeia de valor global; governança; upgrading; agrobiotecnologia de sementes; barreiras de entrada.

\section{Introducción}

Las empresas transnacionales fueron el vehículo que coadyuvó de manera indiscutible al proceso de virtual desvanecimiento de las fronteras nacionales. Ello fue posible a partir de un proceso fragmentado de producción de bienes y servicios articulados entre sí, transformando la matriz de comercio e inversiones en un fenómeno sistémico e integrado. El modelo denominado cadena global de valor (CGV) investiga las diferentes formas en las que se integran y se relacionan los sistemas de producción y distribución mundial. Las empresas trasnacionales, como actores privilegiados de este proceso, son responsables de la coordinación entre las actividades emplazadas en diversas geografías, creando estructuras de gobierno capaces de limitar la participación de nuevos actores y/o la mejora dentro de la cadena. Esta situación plantea nuevos desafíos para las empresas de los países en desarrollo. Entre los paradigmas tecnoproductivos emergentes, donde se hace manifiesta esta división internacional de actividades, se encuentra la biotecnología en semillas. Desde sus comienzos, el sector fue testigo de una continua concentración empresarial donde un reducido grupo de multinacionales controla los paquetes biotecnológicos, así como otros activos clave a lo largo de toda la cadena productiva.

La perspectiva de CGV permite distinguir oportunidades y obstáculos para mejorar las capacidades locales, sobre todo en actividades que son competencias exclusivas de las empresas transnacionales. Estos esquemas fragmentados de producción requieren necesariamente de una coordinación entre las actividades desarrolladas por distintas empresas alrededor del mundo. El concepto de gobernanza deriva de esta ineludible articulación de funciones, haciendo referencia al poder de decisión sobre los vínculos comerciales que se establecen dentro de las CGV. El punto de partida es que algunas empresas, directa o indirectamente, influyen en la organización de la producción global, la logística y los sistemas de comercialización, creando estructuras de 
gobierno con capacidad de tomar decisiones con importantes consecuencias, que van desde el consentimiento de participación de determinadas empresas en la cadena - generalmente de países en desarrollo_ hasta el establecimiento de una gama de actividades que estas pueden llevar a cabo.

Autores como Gereffi, Humphrey y Sturgeon (2005) han demostrado que la parte dominante de una cadena no solo influye en la interacción coordinada entre los eslabones, sino que se vuelve responsable de las actividades de mejora (upgrading) dentro de los eslabones individuales; ergo, la gobernanza en las CGV crea barreras para el upgrading. En consecuencia, diferentes formas de gobierno tienen diferentes implicaciones de upgrading y son las firmas líderes quienes, principalmente y en su carácter de coordinadoras de las CGV, estructuran las oportunidades de mejora de los productores locales (Humphrey \& Schmitz, 2002). La continua concentración empresarial del sector agrobiotecnológico en semillas induce a pensar en la existencia de barreras de entrada que restringen el ingreso a nuevos actores.

El objetivo aquí trazado apunta a identificar esas barreras de entrada que enfrentan los actores productivos de Argentina para participar en eslabones de alto valor agregado de la CGV. Durante el desarrollo del presente se identificarán dos grupos de barreras: aquellas que son consecuencias inherentes a la agrobiotecnología en semillas y aquellas que se derivan de la estructura de gobierno en la CGV, las cuales condicionan la participación de los actores productivos en determinadas actividades. Estas últimas son resultado de la gobernanza de la cadena, determinando, por ende, las posibilidades de upgrading. $\mathrm{La}$ creciente atomización de los procesos productivos, deslocalizados territorialmente pero estrechamente interconectados, nos compele a pensar en modelos económicos que contribuyan no solo a comprender dicho fenómeno y a indagar sobre las relaciones que se suceden entre los actores que participan de las cadenas productivas, sino también a diseñar estrategias de desarrollo que favorezcan a una mejor inserción internacional. 


\section{Cadena global de valor}

El estudio de las CGV se remonta a la década de los setenta, donde puede signarse el comienzo de la globalización y la internacionalización de la producción. Durante esos años comienza a producirse un fraccionamiento de la producción alrededor del mundo, aprovechando la reducción en los costos de las comunicaciones, las revoluciones en el transporte de carga, el creciente uso de tecnologías para el manejo de información cada vez más compleja, entre otros factores. Desde la llegada del nuevo milenio, ${ }^{1}$ varias investigaciones han sostenido que el comercio internacional de bienes y servicios no debe ser visto únicamente como una multitud de transacciones independientes en un mercado global. En efecto, una parte importante del comercio mundial se lleva a cabo dentro de las empresas multinacionales o a través de los sistemas de gobierno que vinculan a estas con empresas locales por medio de una variedad de compras y contrataciones acordadas. Entonces, "si la globalización en la esfera productiva implica la integración funcional entre actividades dispersas internacionalmente, la perspectiva de cadena de valor es un medio eficaz para conceptualizar las formas que esta integración conlleva” (Gereffi et al., 2001).

Una CGV describe a toda la gama de actividades que las empresas y los trabajadores realizan para llevar un producto desde su concepción hasta su uso final. Incluye actividades tales como el diseño, la producción, la comercialización, la distribución y el apoyo al consumidor final. Las actividades que la integran pueden ser realizadas dentro de una misma empresa o divididas entre diferentes, que a su vez pueden ser ejecutadas dentro de una única ubicación geográfica o ser distribuidas en diversas áreas del globo — The Global Value Chains (GVC)

\footnotetext{
1 Entre el año 2000 y 2001, un grupo de investigadores que trabajaba en diversos conceptos relativos a cadenas de valor se reunieron para definir una postura común. Su enfoque se centró en la producción y amplió el foco de análisis a toda la gama de actividades que van desde el diseño hasta la comercialización.
} 
Initiative-.${ }^{2} \mathrm{La}$ OMC, OCDE, UNCTAD, $\mathrm{Cepal}^{3}$ han elaborado una serie de documentos sobre el tema con el objetivo de medir la importancia de las cadenas globales de valor en el comercio mundial. Su perspectiva plantea una visión optimista de la globalización, las CGV y sus efectos potenciales sobre el desarrollo económico. Si bien su propuesta teórica no es objeto de análisis del presente trabajo, los supuestos que promulgan permiten tomarlos como un punto de referencia para un análisis integral de esta herramienta analítica. Desde su visión, la mera participación de los países en desarrollo en las cadenas globales de valor actuaría como un mecanismo de acceso a los mercados internacionales de bienes y servicios. Por lo tanto, los gobiernos no deben fomentar el establecimiento de una cadena de valor completa, sino participar en determinadas actividades y procesos.

A pesar de los potenciales beneficios económicos, sus efectos distributivos y derrames sobre las economías domésticas no siempre son homogéneos. De acuerdo con Padilla (2014, p. 86): “Estos beneficios no son el producto espontáneo e inmediato del proceso de inserción en las cadenas (locales, regionales o globales), sino que requieren del adecuado funcionamiento de diversos factores como el sistema de relaciones de los actores, las instituciones de apoyo, los espacios de apropiación de valor agregado y, en general, de la gobernanza de la cadena".

La heterogeneidad en la distribución de los beneficios es sostenida por autores neoschumpeterianos, ${ }^{4}$ quienes plantean que no todas las actividades dentro de una CGV presentan las mismas ventajas para las economías nacionales. Así, algunas actividades de la parte superior de la cadena — diseño, investigación y desarrollo, producción de componentes avanzados — y de la parte inferior de la cadena — marketing

\footnotetext{
2 The Global Value Chains Initiative es una red informal de investigadores, activistas y formuladores de políticas que busca consolidar y fomentar la perspectiva CGV, una visión centrada en la industria de la globalización económica que pone de relieve los vínculos entre los actores económicos y en todo el espacio geográfico (www.globalvaluechains.org).

3 OMC (2013), OCDE (2012, 2013), UNCTAD (2013), Cepal (2013).

4 Bajo el rótulo de 'neoschumpeterianos' se hace referencia a Gary Gereffi, Raphael Kaplinksy, Timothy Sturgeon, John Humphrey, entre otros.
} 
y distribución — tienden a generar mayor valor agregado que aquellas intermedias, por ejemplo, el ensamblado. Por lo tanto, la ubicación que tengan las empresas en las CGV determinará los beneficios para las economías nacionales.

Las principales rentas económicas primarias en las CGV se encuentran en áreas distintas a la producción, tales como el diseño, el desarrollo de marcas y el marketing (ver por ejemplo Kaplinsky \& Morris, 2001). Conscientes de esta situación, las empresas líderes tienden a externalizar todos aquellos aspectos del proceso de producción que no contribuyan a optimizar las rentas de las empresas (en general, los activos tangibles).

Esta situación genera una asimetría en la estructura de mercado de las CGV: mientras que existe una gran dispersión de la producción - competencia - en los sectores manufactureros de bajo valor agregado (es decir, entre los proveedores), se observa una fuerte tendencia hacia la concentración —oligopolio— de la industria a nivel global (v.g., entre las empresas líderes) (Milberg, 2004). Las firmas líderes, generalmente situadas en los países industrializados, son las que manejan las actividades intangibles, mientras que las empresas de los países en desarrollo se sitúan en eslabones altamente competitivos de la cadena, lo que los puede llevar a enfrentarse a una situación de "crecimiento empobrecedor". He aquí la clave, según esta escuela neo-schumpeteriana, de la creciente desigualdad en la distribución de beneficios derivados de la inserción en las CGV (Dalle, et al., 2013, p. 8).

Planteadas las asimetrías entre las diversas actividades productivas deslocalizadas, el análisis de una CGV ayuda a entender de qué manera un país participa en una industria global, así como también cuál es su papel en la distribución de beneficios que se derivan de ella. La participación en distintos eslabones repercute de forma directa en la organización industrial de un país, al igual que en su potencial de desarrollo económico y social, debido a que las actividades asociadas con cada eslabón emplean diversas combinaciones de recursos (humanos, naturales y capital). La profundización de los encadenamientos 
productivos existentes y el estímulo a la formación de nuevos, combinada con la incorporación de innovaciones tecnológicas, permite el escalamiento hacia actividades más complejas dentro de la cadena global de valor (Cepal, 2013). Es por ello que los autores neoschumpeterianos consideran el estudio de las CGV una herramienta conceptual indispensable para comprender las oportunidades de desarrollo de las economías menos avanzadas.

Un patrón común entre los organismos internacionales y los autores neoshumpeterianos es que, al centrarse en la cadena como unidad de análisis, la investigación se orienta en dos direcciones. Por un lado, en las interdependencias dentro del sector productivo, especialmente el modo en que las firmas y países son integrados globalmente. Ello deriva en el estudio de aspectos como el poder, la gobernanza y la dinámica de las cadenas. La lupa de la CGV permite revelar la dinámica de flujo de las actividades económicas, organizacionales y coercitivas entre productores, intermediarios y consumidores a escala global. Por otro lado, es necesario identificar las formas de acceder a las actividades de alto valor agregado en las cadenas, lo cual se logra a través del proceso denominado upgrading, desarrollando actividades más rentables que lleven al crecimiento sostenido en los niveles de ingreso de los países. En consecuencia, será necesario ahondar en dos conceptos fundamentales que conforman el eje del análisis de las CGV: el concepto de gobernanza y el de upgrading.

\section{Gobernanza}

El concepto representa el poder de decisión sobre los vínculos comerciales que se establecen dentro de las CGV. A partir de la organización interna de estas, el poder de decisión podrá ubicarse en los agentes que realizan las primeras etapas de producción o bien en aquellos que se encuentren en las fases finales de distribución y comercialización (López et al., 2009). El punto de partida es que algunas empresas, directa o indirectamente, influyen en la organización de la producción global, la logística y los sistemas de comercialización, creando estructuras de gobierno con capacidad de tomar decisiones con importantes 
consecuencias, que van desde el consentimiento de participación de determinadas empresas en la cadena — generalmente de países en desarrollo- hasta el establecimiento de una gama de actividades que estas pueden llevar a cabo. La influencia puede materializarse a partir del establecimiento de tres parámetros clave y su consecuente ejecución, los cuales se pueden aplicar en cualquier punto de la cadena. Ellos son: la definición de qué se va a producir (características de los productos), en qué cantidad y la forma en que se va a producir (en referencia a los procesos de producción, la tecnología involucrada, normas de calidad, entre otros aspectos relevantes). La razón principal para la especificación de parámetros a lo largo de la cadena es para contener riesgos, en relación con factores tales como la calidad, el tiempo de respuesta y la fiabilidad de la entrega. En resumen, las estructuras de gobierno de la cadena son las relaciones y mecanismos institucionales a través de los cuales se logra la coordinación de la cadena.

Así mismo, el concepto de gobernanza tiene implicaciones que van más allá de la idea de cooperación, existiendo una asimétrica distribución de poder dentro de la cadena. Generalmente, son grandes corporaciones las que asumen el liderazgo en la organización de la división del trabajo entre las empresas participantes, ejerciendo un mayor o menor control sobre el desarrollo de las actividades, la estructura y la dinámica de la cadena. A su vez, este papel protagonista les permite retener una mayor porción del valor agregado total generado en la cadena. La autoridad de las empresas para ejercer este dominio sobre las CGV se deriva de dos atributos: su poder de mercado — medido en parte por la concentración o la cuota de mercado- y su posicionamiento en los segmentos de la cadena. Ese poder se ejerce por diversas vías: a través del control de las empresas líderes sobre los recursos clave necesarios en la cadena, a partir de la prestación de apoyo técnico a los proveedores a fin de que puedan alcanzar el rendimiento requerido, etc. Como consecuencia de esta situación, se crean distintas estructuras de gobierno dentro de las CGV, que suponen diferentes niveles de coordinación entre las actividades realizadas dentro de ellas. Dichas estructuras no son estáticas, sino que pueden modificarse a lo largo del tiempo, lo cual dependerá no solo de los cambios en las estrategias de las empresas involucradas, 
sino también de factores institucionales, tecnológicos, innovaciones organizacionales, etc. (Gereffi, et al., 2005).

Las empresas transnacionales comenzaron a redefinir sus competencias básicas para centrarse en la innovación, el marketing y los segmentos de mayor valor añadido de manufactura y los servicios, reduciendo su propiedad directa respecto de funciones básicas, tales como los servicios genéricos y el volumen de producción (Gereffi, et al., 2005). Ello produjo un creciente traslado de los procesos de fabricación manufacturera desde los países desarrollados hacia proveedores que podían satisfacer las especificaciones requeridas y utilizar las tecnologías de proceso adecuadas (Gereffi et al., citados en Sturgeon, 2008). Con el objetivo de utilizar un esquema que permita explicar los cambios en las redes de acuerdos globales de producción, en este trabajo se emplearán los modelos diferenciados de gobernanza propuestos por Gereffi et al. (2005). ${ }^{5}$ La contribución de Gereffi ha permitido avances sustanciales en el uso analítico y normativo del concepto de cadenas de valor, puesto que se ha focalizado particularmente en las relaciones de poder que se encuentran dentro de la cadena de valor, centrándose en la coordinación de la producción globalmente dispersa, pero eslabonada, de los sistemas de producción.

Según los investigadores, un primer punto para tener en cuenta en el marco de las relaciones entre las empresas es la especificidad de activos, que los identifica con los costos económicos de transacción. Ellos hacen referencia a los costos involucrados en la coordinación de actividades a lo largo de la cadena, los cuales se incrementan cuando las cadenas de valor elaboran productos que no son estándar. A pesar de que los directivos generalmente valoran la capacidad de cambiar de proveedores cuando las condiciones lo permiten, se ha desarrollado una necesaria tolerancia con aquellos socios con los que poseen inversiones vinculadas a sus relaciones comerciales. Si bien la gobernanza identifica el problema de la especificidad de los activos como un aspecto importante, no se trata del único. Se presentan tres variables

\footnotetext{
Existen otros tipos de gobernanza que plantean la coordinación de actividades económicas entre empresas, como los esgrimidos por Jessop, Williamson, Humphrey y Schmitz.
} 
que determinan de forma dinámica el contenido y el carácter de los vínculos entre empresas, a saber: 1) la complejidad de la información y la transferencia de conocimientos necesaria para sostener una determinada operación, particularmente con respecto a los productos y especificaciones del proceso; 2) la medida en que esta información y el conocimiento pueden ser codificados y, por lo tanto, que se transmite de manera eficiente y sin inversión de transacciones específicas entre las partes en la transacción; y 3) las capacidades de los proveedores en relación con los requerimientos de los líderes de la cadena. ${ }^{6}$

Del análisis conjunto de estas tres variables, Gereffi et al. han identificado cinco formas genéricas de gobernanza: a) coordinación mediante el mercado, b) cadenas de valor modulares, c) cadenas de valor relacionales, d) cadenas de valor cautivas y e) cadenas de valor jerárquicas. Los autores reconocen que, al tratarse de tipos ideales de gobernanza, estos son conceptualizaciones que necesariamente deben contrastarse con situaciones de la realidad. A su vez, dada la complejidad de las industrias y la amplia variación en los patrones de gobernanza en las diferentes etapas de la cadena de valor, resulta difícil caracterizar industrias enteras de acuerdo con un solo tipo. La comprensión de la gestión de una cadena ayudará a vislumbrar la distribución de las ganancias a lo largo de esta. En relación con ello, Kaplinsky (2000) sugiere que la capacidad de gobernar a menudo se basa en las competencias intangibles (I+D, diseño, marca, marketing), que se caracterizan por altas barreras de entrada y de altos rendimientos, generalmente obtenidas por las empresas de países desarrollados. Por el contrario, en los países en desarrollo las empresas tienden a ser bloqueadas en las actividades tangibles de producción, bajo los parámetros establecidos por los gobernantes, cuyas barreras de entrada son bajas y obtienen bajos rendimientos.

\footnotetext{
6 Altenburg (2006, citado en Luna, 2009) señala otros factores condicionantes del régimen de gobernanza, como la transparencia del mercado y los costos de búsqueda, la incertidumbre acerca del desarrollo del mercado, la estructura del mercado o las condiciones del marco institucional.
} 
Acorde a esta nueva división internacional del trabajo, otra de las contribuciones de Gereffi et al. (2005) es que han logrado demostrar que la parte dominante de una cadena no solo influye en la interacción coordinada entre los eslabones, sino que se vuelve responsable de las actividades de mejora o upgrading dentro de los eslabones individuales. Se puede argumentar que la gobernanza en las CGV crea barreras para el upgrading local. Ergo, diferentes formas de gobierno tienen diferentes implicaciones de upgrading y son las firmas líderes quienes, en su carácter de coordinadoras de las CGV, estructuran las oportunidades de mejora de los productores locales (Humphrey \& Schmitz, 2002).

\section{Upgrading}

El upgrading hace referencia a todas aquellas acciones que promueven la realización de mejores productos, métodos para hacerlos de manera más eficiente o avances que permitan la incorporación de actividades más calificadas. Las innovaciones no plantean necesariamente una disrupción absoluta con los productos y procesos existentes, sino que también se hace mención a aquellas mejoras marginales y evolutivas para una empresa, y que le permiten mantenerse al día con las demandas y las normativas internacionales. El aprendizaje y la adquisición de capacidades tecnológicas pueden ser estimulados a través de la participación en las CGV. Así mismo, según Mancini (2016), se acuñó el concepto de upgrading (escalamiento) para describir las mejoras de las competencias y de la posición de las empresas en las industrias globales. Si bien el upgrading está vinculado intrínsecamente al concepto de 'mejoras', en el marco de las CGV, dichas mejoras conllevan un escalamiento en los eslabones productivos de las cadenas de actividades hacia actividades con mayores rentas.

El modo en que una empresa forma parte en las cadenas de valor es muy relevante, no solo para determinar su trayectoria de aprendizaje, sino también sus posibilidades para insertarse en el mercado mundial. López y Ramos (2009) indican que dicha inserción debe comprenderse como un fenómeno bidimensional: por un lado, el impacto para el país se relaciona con el tipo de CGV en la que participa la empresa, mientras que, por el otro, también es sumamente relevante el eslabón 
que ocupa la empresa en la cadena. En resumen, se ponen en evidencia dos factores principales al momento de analizar la participación de una empresa en una CGV: el tipo de cadena en la cual la empresa está inserta y el eslabón en el que participa.

De acuerdo con Kosacoff et al. (2007), esas mejoras se pueden encuadrar en cuatro alternativas, a saber: a) producir con mayor eficiencia a partir de una mejora de los procesos internos (upgrading de procesos); b) orientarse a líneas de productos con mayor valor unitario, introduciendo nuevos productos o mejorando los productos más rápido que los rivales (upgrading de productos); c) desplazarse hacia tareas que requieran mayores capacidades, incrementando el valor agregado a través del cambio de actividades dentro de la firma - por ejemplo, realizar tareas de diseño o marketing- (upgrading funcional); o d) aplicar las competencias adquiridas en una función particular para desplazarse hacia otro sector (upgrading intersectorial). A modo de resumen, como señalan Pietrobelli y Rabelloti (2006), "el upgrading, en última instancia, debería implicar un proceso de alejamiento de las actividades en donde la competitividad depende de los costos y las barreras de entrada son bajas".

Los procesos de upgrading, al generar una producción con un mayor valor agregado, permiten alcanzar nuevas rentas y modificar las estructuras de las CGV. Ello implica una superación respecto del concepto estático de Ricardo de la ventaja comparativa, dado que el éxito en la mejora a nivel de empresa permite la adquisición dinámica de competitividad en nuevos nichos de mercado, sectores o fases de la cadena productiva (Lall et al., 2004; Pietrobelli \& Rabellotti, 2006). En palabras de Kaplinsky y Morris (2001, p. 28), se puede sostener que "las cadenas de valor son depósitos para la renta, y esas rentas son dinámicas”.

Las empresas para incrementar sus rentas y sostenerlas en el tiempo impulsan actividades con barreras de entrada duraderas. Si las barreras de entrada son transitorias, las firmas irán desarrollando la capacidad dinámica para moverse sistemáticamente hacia aquellas actividades en las que prevalecen altas barreras a la entrada. Por consiguiente, la 


\section{4 / Santiago Calvo}

determinación de las barreras de entrada limita la presión competitiva quedando, por lo tanto, aislados en cierta medida de las presiones externas. Una de las claves del cambio que estamos observando en un mundo globalizado y competitivo es la transición de la acumulación de rentas de actividades tangibles hacia aquellas actividades intangibles que surgen en la cadena de valor. Diversos estudios ${ }^{7}$ han observado que el conocimiento intangible está crecientemente caracterizado por altas barreras al ingreso, y que los propietarios de este conocimiento obtienen más renta de la globalización de la producción y el intercambio (Kaplinsky \& Morris, 2001). La habilidad para identificar actividades ricas en rentas a lo largo de toda la cadena de valor brinda la clave para comprender la apropiación global de las ganancias de la producción. Para estos autores, aquellos que controlan las rentas y que tienen la capacidad de crear nuevas rentas cuando caen las barreras de entrada son los principales beneficiarios.

En suma, las rentas se concentran en las áreas intangibles de las cadenas de valor, cuyos derechos de propiedad intelectual poseen una larga duración, representando una absoluta e inmutable forma de renta económica. Para Srinivasan (2003), el control de los derechos de propiedad intelectual les permite a las empresas líderes reforzar los mecanismos de consolidación industrial, yuxtaponiendo patentes e incrementando los costos y las barreras de entradas, negando nuevas oportunidades a empresas pequeñas que deseen competir con las industrias líderes. En efecto, según Lastres et al. (citados en Humphrey \& Schmitz, 2002), ello se basa en que mientras la producción es crecientemente globalizada, las estrategias de innovación se mantienen concentradas en los países sede de las firmas líderes.

\footnotetext{
Upgrading in global value chains: lessons from Latin American clusters, de Giuliani, Pietrobelli y Rabellotti (2005); A handbook, for value chain research, de Kaplinsky y Morris (2001), entre otros.
} 


\section{Moderna biotecnología}

La revolución productiva de finales del siglo XIX y principios del XX vino de la mano de importantes invenciones provenientes de la física, la mecánica y la química. A diferencia de ello, en las postrimerías del siglo Xx y comienzos del XXI, las mayores transformaciones productivas se derivan de nuevas disciplinas como la informática, la robótica, la nanotecnología y la biotecnología. Estas se caracterizan no solo por su convergencia y transversalidad entre sí, sino también porque demandan un elevado umbral de conocimientos científicos para su aplicación, singularidad que pone de relieve el rol central que juega el conocimiento científico en el ámbito productivo. La agrobiotecnología es consecuencia de la confluencia de desarrollos realizados en diversas disciplinas y sus aplicaciones prácticas. Su pronta difusión entre los países de base agrícola dio paso a una nueva revolución agrícola.

$\mathrm{Al}$ adentrarse al proceso productivo de semillas genéticamente modificadas (GM) se pueden distinguir con claridad las diversas etapas que lo conforman, ${ }^{8}$ observando la primacía que ocupan las actividades de $\mathrm{I}+\mathrm{D}$ durante las primeras fases. Cada fase exige diversas capacidades y escalas técnicas, tanto productivas como comerciales, las cuales pueden ser ejecutadas por un mismo agente económico o por varios. Dentro de esta cadena productiva, la adaptación local de los cultivos generó espacios para una necesaria participación de actores locales, quienes disponían de un profundo y acumulado conocimiento en materia de germoplasma de semillas autóctonas. En consecuencia, sobrevino una nítida división del trabajo: mientras las empresas transnacionales se concentraron en el desarrollo de semillas genéticamente modificadas basadas en la manipulación de genes, los actores locales se dedicaron a la comercialización de las semillas en cada región a partir del control de las variedades y otros activos complementarios necesarios (Bisang \& Varela, 2006).

\footnotetext{
8 El proceso productivo de semillas GM tiene diversas etapas: desarrollo de nuevos materiales genéticos, producción y multiplicación, almacenado y comercialización.
} 
La creciente preeminencia que adquirieron los conocimientos científicos en el mundo productivo condujo a la revalorización del sistema sectorial de innovación como eje para el desarrollo y la creación de ventajas competitivas del sector. Ello se tradujo en una ineludible mutación de los roles tradicionales de los espacios públicos, caracterizados por su exclusiva dedicación a la producción de conocimiento a partir del fomento de la investigación científica, soslayando o dejando rezagadas las actividades de investigación aplicada o transferencia de tecnología a los sectores productivos. De esta manera, se replantearon las formas de investigar, los roles de los investigadores y la dinámica de alianzas entre empresas y universidades, institutos científicos y laboratorios. Al evaluar los cambios tecnológicos inherentes al sector estudiado, es plausible concluir que el mejoramiento continuo de la calidad y la progresiva sofisticación de los productos sean solo el resultado de los recursos internos de una empresa o del acceso relativamente irrestricto a las tecnologías disponibles.

\section{Sistema sectorial de innovación argentino de agrobiotecnología}

En Argentina, la biotecnología aplicada al agro puede rastrearse desde comienzos del siglo xx cuando el Estado nacional se hizo cargo de los procesos locales de $\mathrm{I}+\mathrm{D}$ orientados al desarrollo de germoplasma adaptado a las condiciones de la producción local. Para los años cuarenta se había configurado un sector de agrobiotecnología con cierta capacidad tecnoproductiva, dominado por el sector público y con una reducida cantidad de empresas de capital nacional dedicadas principalmente al mejoramiento de semillas (Lengyel, 2013). Hasta entrada la década de los ochenta, si bien el sector público continuó siendo el eje de la industria, la articulación pública-privada dio paso a la creación y liberación de nuevas líneas de semillas.

Según Lengyel (2013), la estructura del sector comprendía por entonces tres componentes: 1) el más importante era el sistema público, con preeminencia del Instituto Nacional de Tecnología Agropecuaria (INTA) y, en menor medida, de algunas universidades nacionales; 
2) una quincena de empresas medianas de capital local que trabajaban en los principales cultivos sobre la base de variedades de su propio desarrollo; y 3) una decena de firmas transnacionales que introducían en el mercado desarrollos llevados a cabo en sus países de origen con los correspondientes procesos de adaptación al medio local. Estos tres grupos de actores constituían la industria semillera. Concentraban las actividades de control y desarrollo de variedades, nuevas tecnologías de proceso, capacidad de análisis y de testeo. Esta plataforma permitía avizorar un sistema sectorial de innovación preparado para una rápida adaptación hacia la moderna agrobiotecnología durante los años venideros. En contraposición a las capacidades adquiridas en la materia, las políticas de los años noventa afectaron negativamente la llegada de las semillas transgénicas a Argentina. Las reformas neoliberales debilitaron la preeminencia del Estado nacional en materia de generación y difusión de innovaciones que había alcanzado hasta entonces, mientras que a su vez se favoreció el ingreso de empresas transnacionales.

A finales de esa década, megacorporaciones internacionales comenzaron a absorber firmas semilleras locales con la finalidad de integrar verticalmente el sector y centralizar el control del conocimiento y la tecnología genómica. Como principal estrategia comercial promovieron la aplicación de los paquetes tecnológicos conformados por semillas, herbicidas y fertilizantes asociados, permitiendo ampliar su rango de negocios. Por su parte, un puñado de empresas nacionales se orientaron a desarrollar germoplasma y a producir cultivares transgénicos, aplicando los genes obtenidos por terceros a variedades vegetales propias, mientras que un acotado número de empresas se concentraron en realizar esfuerzos en $\mathrm{I}+\mathrm{D}$ para descubrir nuevos genes de interés para el mejoramiento de los cultivos. Contrariamente a esta división de actividades entre actores nacionales y extranjeros, la evidencia recogida por Lengyel (2013) le permite argumentar que el diseño y el desarrollo de semillas por medio de esquemas en red es una fuente esencial de la capacidad de innovación de productos a nivel de la firma individual. Por consiguiente, el proceso de innovación se encauza hacia formas cada vez más reticulares, comprendiendo los 
dos principales segmentos de la industria: la producción de semillas transgénicas y la generación de variedades. ${ }^{9}$

Por su parte, el sistema sectorial de innovación en Argentina dispone de una importante masa crítica y de positivos resultados en materia de investigaciones biotecnológicas, principalmente en la fase inicial que involucra el pasaje de la idea al laboratorio. Sin embargo, para asegurar el proceso integral de $\mathrm{I}+\mathrm{D}+\mathrm{i}$ se torna necesario realizar el escalado de los desarrollos, fase en donde se simulan las condiciones del proceso a nivel productivo. Esta asimetría entre ambos procesos representa un problema en la interfase científica con la tecnológica y entre esta y la aplicación productiva concreta, dificultando las actividades de transferencia tecnológica.

En este país, los altos umbrales científicos en materia de calidad y cantidad de científicos y tecnólogos, así como los requerimientos de inversión, se satisfacen a partir de las investigaciones de centros especializados y universidades públicas, mientras que las fases posteriores provienen de empresas privadas. De esta manera, el sistema se vuelve un círculo de retroalimentación que rompe con la forma tradicional de articulación entre etapas segmentadas. La generación de innovaciones tecnológicas avanzadas en Argentina requiere de manera indispensable de la participación de ambos sectores. Por un lado, para poder generar riqueza basada en el conocimiento, el sector productivo requiere de la investigación profesionalizada, la cual está mayoritariamente concentrada en instituciones del sector público. Por el otro, el sector de investigación público no puede incursionar en la producción de tecnología sin el respaldo económico y la experiencia práctica del sector productivo (Mentaberry, 2010).

Esta política de articulación permitió a la red coordinada por la empresa Bioceres crear una joint venture con los institutos de biotecnología y

\footnotetext{
$9 \quad$ En un estudio del mismo autor realizado en 2016, refuerza su postura al plantear que "la capacidad de escalamiento tecnológico e innovación de las empresas está fuertemente relacionada con el desarrollo de formas colaborativas de producción (estructuras industriales desintegradas o en red)".
} 
de genética del INTA, a fin de desarrollar maíz transgénico resistente a ciertos virus locales, disponiendo con el financiamiento de inversores privados como capital de riesgo. De igual modo, por medio de un acuerdo con la Universidad Nacional del Litoral y el Consejo Nacional de Investigaciones Científicas y Técnicas (Conicet) se han desarrollo variedades de trigo, maíz y soja resistentes a la sequía; y se han empleado tres programas estratégicos de la Agencia Nacional de Promoción de la Investigación Científica y Técnica (ANPCyT) para impulsar la interacción de instituciones generadoras de conocimiento en las áreas de cultivo de trigo y girasol, y en la exploración genómica de suelos (Lengyel, 2013).

Por su parte, el INTA transitó la misma dirección y adecuó su estructura institucional al nuevo escenario. La creación de los convenios de vinculación tecnológica le permitió a esta institución pública impulsar y formalizar emprendimientos de $\mathrm{I}+\mathrm{D}$ con el sector privado, favoreciendo la viabilidad de la cooperación público-privada para la innovación a nivel micro. En términos generales, se puede sostener que la investigación en Argentina surge y se desarrolla principalmente en centros especializados y universidades públicas, mientras que la tecnología utilizada proviene de grandes empresas extranjeras.

A nivel local se realizan tareas de adaptación de la tecnología desarrollada en otros países, sin lograrse un real progreso local de ella. "Por más que el país tiene capacidades para desarrollar tecnologías propias en biotecnología vegetal, y de hecho ha logrado desarrollar cultivos transgénicos propios, son muy pocas las empresas que se dedican al tema y contadas las innovaciones que hayan llegado o estén cerca de llegar al mercado" (Pellegrini, 2013, citado en Romani et al., 2016).

\section{Cadena global de valor de agrobiotecnología en semillas}

La industria agrobiotecnológica tiene sus orígenes a partir del año 1980, cuando Estados Unidos extendió la protección de patentes a organismos vivos (como genes, líneas celulares, tejidos y organis- 


\section{I Santiago Calvo}

mos sometidos a ingeniería genética) y cuando abrió el camino para la comercialización ${ }^{10}$ (vía patentes o licencias) del conocimiento científico generado en las universidades e instituciones públicas de investigación (Coriat et al., 2003). Por último, otro elemento institucional fundamental para el desarrollo de la agrobiotecnología tiene que ver con el marco regulatorio de biotecnología aprobado en Estados Unidos en el año 1986, que sirvió de modelo para los sistemas regulatorios aplicados en el resto del mundo. Estas transformaciones institucionales se tradujeron en un creciente flujo de conocimiento científico hacia la industria, conformando redes entre corporaciones de biotecnología y universidades (Parayil, 2003, citado en Sztulwark \& Girard, 2017).

El nuevo paradigma científico y productivo nació en el marco de redes público/privadas y de alianzas estratégicas. Ello devino en la creación de nuevas firmas, las cuales fueron resultado de un continuo y dinámico proceso de fusiones y adquisiciones, involucrando empresas de diversas actividades y localizadas en distintos países. A fin de cuentas, estas acciones desembocaron en la conformación de grandes multinacionales, propietarias de los más difundidos paquetes biotecnológicos y de activos clave a lo largo de toda la cadena productiva. En suma, las fusiones y adquisiciones dieron como resultado el surgimiento de grandes multinacionales que evidencian una concentración de actividades aguas arriba de la cadena productiva. Así mismo, con el afán de potenciar sus actividades se entablaron una serie de alianzas entre estas y otras firmas que detentaban activos particulares como canales de comercialización, marcas, agroquímicos complementarios.

Para asegurar su estrategia comercial en el país, las trasnacionales adquirieron semilleras locales o establecieron convenios con estas, replicando localmente los procesos de concentración, fusiones y absorciones operados a nivel internacional. Estas acciones confluyeron en la creación de redes de distribución de alcance nacional, transformándose en

\footnotetext{
10 El Acta Bayh-Dole modificaba las normas sobre propiedad intelectual de las investigaciones financiadas con fondos federales.
} 
un vehículo de relacionamiento directo con los productores agrarios. En pocas palabras, no solo se encontraron en condiciones de ofrecer una amplia gama de insumos y servicios técnicos, sino que a su vez completaron su ciclo de negocios a partir del otorgamiento de financiación a los productores para la compra de insumos.

Por su parte, Argentina dispone de un apreciable conjunto de empresas de biotecnología nacionales, lo cual representa una base significativa para el desarrollo del sector, ubicándola entre los países de avanzada en el desarrollo y lanzamiento comercial de paquetes tecnológicos. Pese a que los eventos liberados son casi exclusivamente impulsados por empresas extranjeras, la presencia de un reducido número de empresas locales que se encuentran en las últimas fases de desarrollo de eventos transgénicos permite realzar las capacidades locales en la materia. El surgimiento del Instituto de Agrobiotecnología Rosario ${ }^{11}$ refleja la dinámica de red imperante en el sector de agrobiotecnología, fortaleciendo la innovación en los procesos tecnológicos y productivos por medio de la articulación público/privada. En 2015 y como resultado de estos avances institucionales, la Comisión Nacional Asesora de Biotecnología Agropecuaria (Conabia) aprobó por primera vez un cultivo biotecnológico nacional: una soja resistente a sequía, la cual fue obtenida por el Indear. Hasta hoy solo Brasil, Cuba, Indonesia, China y Estados Unidos poseen cultivos biotecnológicos nacionales.

Si bien los avances nacionales en materia de desarrollo genético representan la superación de una de las barreras del sector, estos constituyen el primer eslabón de una serie de restricciones que enfrentan los actores económicos para producir y comercializar estos desarrollos. Para poder participar activamente, no solo es necesario disponer de determinadas escalas científico-técnicas, sino que también se requiere de escalas económicas, legales y comerciales. Pellegrini (2013) sostiene que, como resultado de estos importantes condicionantes, "ningún desarrollo argentino llegó a realizar todas las etapas exigidas por la

\footnotetext{
11 La creación del Instituto de Agrobiotecnología Rosario (Indear) en el año 2004 fue resultado de una alianza entre la empresa local Bioceres y el Conicet, y representó un cambio significativo tanto en la cultura empresarial como en la académica.
} 
regulación" (p. 200). De la identificación de las diversas barreras de entrada, son aquellas restricciones de la evolución empresarial las más relevantes para el presente trabajo, puesto que ponen en evidencia la coordinación implícita entre los actores de la cadena de valor. Del análisis de estas, es posible determinar que la presencia de altas barreras de entrada al sector conduce indudablemente a que sea una estructura oligopólica la que asume el liderazgo en la organización de la división del trabajo dentro de la CGV. La autoridad de las multinacionales proviene de su poder de mercado y de su posicionamiento en segmentos clave de la cadena.

La figura 1 busca explicitar las diversas relaciones e interacciones que tienen lugar en la CGV evaluada. Con ella se pretende delimitar con claridad los roles que desempeñan los actores locales e internacionales en cada etapa del proceso productivo.

Figura 1. Roles en la agrobiotecnología en Argentina

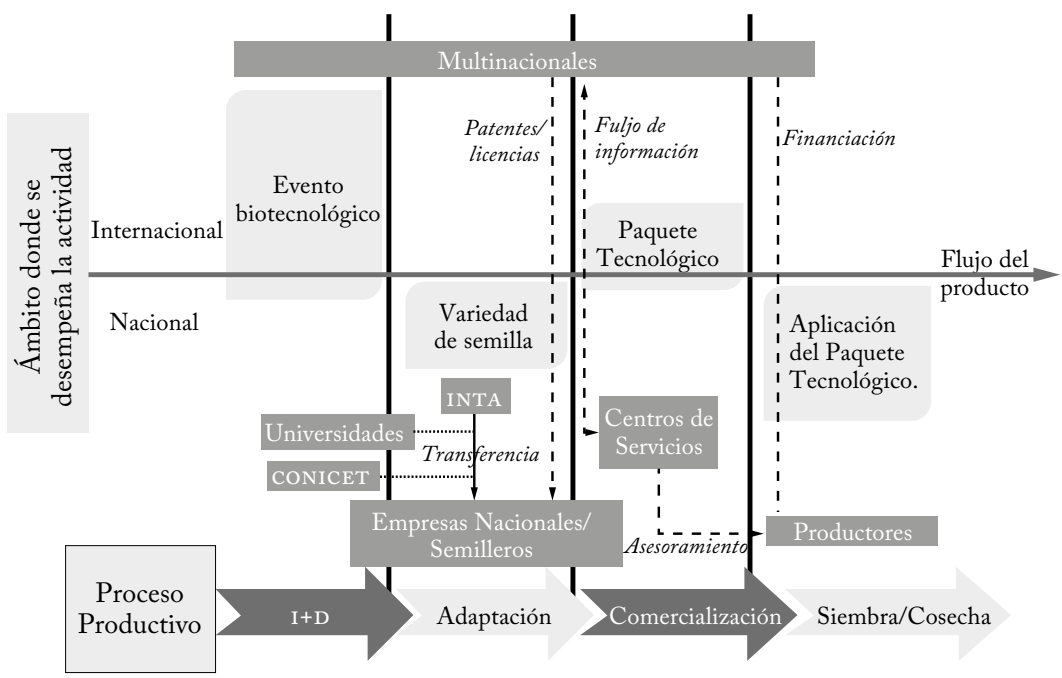

Fuente: elaboración del autor.

\section{Barreras de entrada}

Las barreras de entrada son un concepto de la ciencia económica que refiere a los obstáculos o restricciones que enfrentan los actores 
económicos para ingresar en un nuevo mercado. De acuerdo con Michael Porter (1982), una barrera de entrada a un sector industrial es lo que hace que el competidor potencial tenga que realizar esfuerzos para participar en él. Altas barreras de ingreso mantienen a potenciales rivales fuera de una industria, incluso cuando los rendimientos sean altos, las cuales devienen en ventajas estratégicas y protegen el segmento en forma más segura.

Para el presente trabajo, las barreras de entrada son analizadas entre los diversos eslabones de la cadena de valor de semillas transgénicas, haciendo foco de manera particular en los eslabones aguas arriba de esta, donde se manifiesta el desacople entre innovación y producción. Esta diferenciación entre tipos de capacidades plantea distintas barreras a la entrada en cada caso, suponiendo además una elevación de las barreras de entrada en las actividades de innovación y de caída en las de producción (Sztulwark \& Juncal, 2014). Así, se puede inferir que las barreras de entrada en las actividades de innovación no solo son mayores a las existentes en las actividades de producción, sino que además son cualitativamente diferentes, y, por lo tanto, que la acumulación de capacidades productivas no necesariamente conduce a un dominio de las de innovación (Altenburg et al., 2008, citado en Sztulwark \& Juncal, 2014). Acorde con lo planteado por Gutman (2012), las barreras de entrada en la moderna biotecnología se originan a partir de una conjunción de factores, como son los riesgos asociados a estas tecnologías, los extensos plazos desde el desarrollo hasta la comercialización, al igual que los elevados gastos de I+D, patentamientos y aprobaciones locales de los eventos, necesarios para llegar con una semilla GM al mercado. ${ }^{12}$

Para poder participar activamente en este sector, es necesario disponer de determinadas escalas científico-técnicas, económicas, legales,

\footnotetext{
12 Se ha estimado que se requieren entre 10 y 12 años y entre 30 y 100 millones de dólares, según los casos, para cubrir todo el ciclo desde las etapas iniciales de investigación. Por otra parte, se trata de actividades de investigación intensivas: los gastos estratégicos complementarios. En suma, se trata de mercados oligopólicos fuertemente dominados por grandes jugadores globales (Gutman, 2012).
} 
así como también se precisa de una ineludible complementación con los oferentes locales. La figura 2 muestra una diferenciación entre las barreras propias del sector y las barreras de la CGV en biotecnología en semillas. Las barreras propias del sector responden a características inherentes al sector y son consecuencia directa del área de la biotecnología en semillas. Por otro lado, se pudieron identificar aquellas que son consecuencia de la gobernanza de la $\mathrm{CGV},{ }^{13}$ las cuales son producto de las dinámicas empresariales y productivas. Como es dable esperar, las primeras repercutirán de manera directa en las segundas. No obstante, las segundas son restricciones propias de la evolución empresarial del sector que hacen al análisis del presente trabajo.

Figura 2. Barreras de entrada de acuerdo con eslabones de la cGV

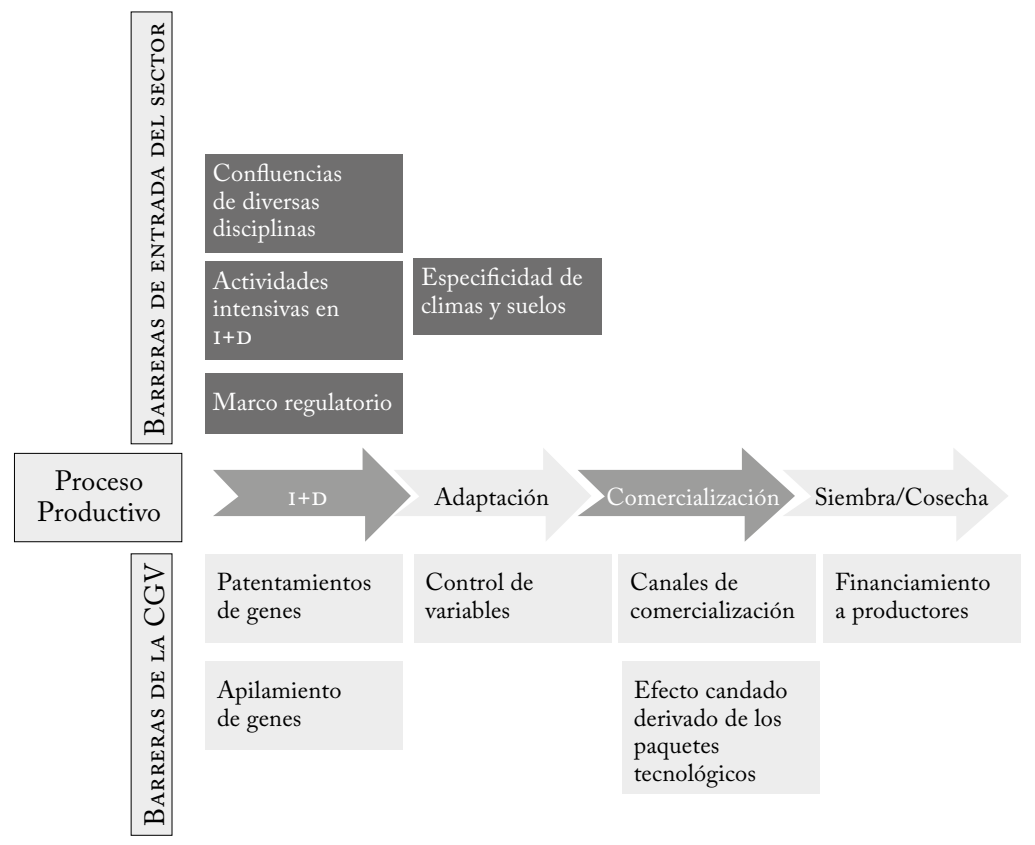

Fuente: elaboración del autor.

\footnotetext{
13 Kaplinsky (2000) denomina barrera de entradas endógenas a aquellas que son creadas directamente por participantes de la cadena de valor.
} 


\section{Barreras de entrada del sector}

\section{- Confluencias de diversas disciplinas}

La moderna biotecnología es resultado de una confluencia de diversas disciplinas, incluyendo una amplia variedad, como la química, la biología, la ingeniería bioquímica y la microbiología. Esta nueva tecnología de naturaleza multidisciplinaria e integradora, que además es convergente y sinérgica con otras tecnologías de punta, se transforma en una primera barrera de entrada al sector.

\section{- Actividades intensivas en $I+D$}

Las actividades biotecnológicas son intensivas en investigación y desarrollo. Para superar las barreras a la innovación tecnológica, se requiere de grandes inversiones en activos intangibles, disponer de una importante base de recursos humanos altamente calificados, afrontar los tiempos inherentes a las investigaciones y la inversión en ensayos, pruebas de campo, etc., representando costos demasiado elevados. En valores absolutos, las inversiones en esta área por algunas empresas son similares a la totalidad del gasto en $\mathrm{I}+\mathrm{D}$ para un país como Argentina (Gutman \& Lavarello, 2007). Esta situación reduce de manera significativa la participación de nuevos actores, dado que son pocas las empresas que pueden enfrentar estas erogaciones. Esta restricción también puede aplicarse al proceso productivo de adaptación.

\section{- Marco regulatorio}

Las patentes representan la protección más utilizada para restringir la participación de nuevos actores en un mercado. Una patente crea una barrera de entrada que obliga a los competidores a desarrollar algo similar o mejor. En esta industria, cada uno de sus principales segmentos opera bajo distintos esquemas de regulación de la propiedad intelectual: mientras que para el desarrollo de eventos transgénicos rigen leyes de propiedad intelectual, para el desarrollo de variedades 


\section{I Santiago Calvo}

existe un sistema sui generis denominado derecho de obtentor. ${ }^{14}$ Esta herramienta se maximiza si existe una activa vigilancia respecto del uso indebido del desarrollo protegido, lo que obliga a los propietarios de la patente a destinar recursos hacia actividades de control y observancia.

Así mismo, por marco regulatorio se hace referencia no solo a los derechos de propiedad, sino también a las condiciones de seguridad, inocuidad y eficiencia de los desarrollos. Las regulaciones se caracterizan por su elevado costo, el cual está vinculado a la complejidad de los ensayos y a los tiempos demandados, dado que estas exigencias regulatorias se extienden desde la etapa de experimentación hasta el consumo final. Ello se traduce en altos costos y tiempos de lanzamiento para las nuevas semillas, que se ven multiplicados en función del número de países importadores de la tecnología y de los productos finales. De igual forma que en la anterior barrera, esta restricción también puede aplicarse al proceso productivo de adaptación y de comercialización.

\section{- Especificidad de climas y suelos}

La aplicación de un gen o evento biotecnológico, producto del control del conocimiento y la tecnología genómica, requiere indiscutiblemente de su aplicación en determinadas variedades de semillas que respondan a las especificidades de los suelos en donde se aplicarán. Tanto el clima como los suelos varían de una región a otra, sin realizar distinciones de geografía política, lo que implica la necesidad de generar variedades adaptables a dichas características. Esto no es un proceso rápido, sino que demanda años de esfuerzos, confluyendo en bancos de germoplasma, los cuales son propiedad de instituciones

\footnotetext{
14 En Argentina, para el desarrollo de semillas transgénicas rige la Ley de Patentes de Invención y Modelos de Utilidad, modificada en 1996, que otorga protección de acuerdo con los estándares internacionales. En el caso del desarrollo de variedades, rige la Ley de Semillas y Creaciones Fitogenéticas, que protege el trabajo de los fitomejoradores por períodos que van de 10 a 20 años. Sin embargo, este último no impide que otras personas puedan utilizarlo para generar un cultivar distinto o que los productores puedan retener semilla para su propio uso en el período siguiente.
} 
públicas de investigación o de firmas locales que poseen fortalezas en tareas de fitomejoramiento. Por ende, para hacer frente a esta barrera, la producción de semillas transgénicas conlleva inevitablemente una articulación con estos actores locales.

\section{Barreras de la cadena global de valor}

Si bien inicialmente los desarrollos de la agrobiotecnología reproducen la dinámica industrial registrada en la farmabiotecnología, en la cual coexisten grandes empresas y pequeñas firmas especializadas en el marco de mercados de conocimiento, su evolución posterior mostrará una tendencia hacia la concentración asociada, por un lado, al reforzamiento de las barreras que se oponen a la entrada "aguas arriba", impulsado por la posibilidad de patentamiento de los genes y el consecuente control de las variedades de los principales cultivos; y por el otro, a las estrategias de alianzas y fusiones, por parte de las empresas de agroquímicos que les permitirán valorar su I+D a partir de la integración "aguas abajo" de activos complementarios y redes comerciales (Gutman \& Lavarello, 2007, pp. 12-13).

La concentración empresarial ${ }^{15}$ en un puñado de grandes firmas multinacionales tuvo un ineludible impacto en la cadena. Ello les permitió desarrollar barreras de entrada al sector dinámicas, asegurando mayores rentas para estas y complejizando aún más el ingreso de nuevos actores.

\section{- Patentamientos de genes}

La disponibilidad de recursos económicos por las trasnacionales les permitió afrontar los costos derivados de los patentamientos y su

\footnotetext{
15 Al final del nuevo proceso de fusiones y adquisiciones iniciado en 2016, tres empresas controlarán el $60 \%$ de las semillas, el $70 \%$ de los pesticidas y productos químicos para el cultivo de alimentos y casi todas las patentes de los eventos transgénicos (elDiarioes \& The Guardian, 2016).
} 


\section{I Santiago Calvo}

valorización. Esta situación reduce de manera significativa la participación de nuevos actores, dado que son pocas las empresas que pueden enfrentar estos ingentes gastos. A modo de ejemplo, para los tres cultivos en los que se difundió más fuertemente la biotecnología, algodón, maíz y soja, los desarrollos se concentran en un reducido conjunto de genes, cuyas patentes son propiedad de cuatro multinacionales que cuentan con las capacidades regulatorias para valorizar esta tecnología a escala global (Ward, 2000, citado en Gutman \& Lavarello, 2007).

\section{- Apilamiento de genes}

Las empresas propietarias de los eventos patentados reforzaron las barreras a la entrada a partir de estrategias de apilamiento de genes. Las empresas combinan diversos genes en una semilla, que las hacen resistentes a más de un elemento; por ejemplo, maíz resistente a herbicidas y a insectos. Estas innovaciones involucran diversas patentes y son acumulativas, complejizando aún más la producción de semillas de condiciones similares.

\section{- Control de variedades y canales de comercialización}

La absorción de semilleros locales tuvo una doble implicancia para las empresas multinacionales: por un lado, les permitió disponer de una multiplicidad de variedades de semillas adaptadas a las diversas condiciones agroecológicas locales, sobre las cuales se incorporan los eventos desarrollados. Por otro lado, la amplia red de comercialización les permitió integrarse aguas abajo, transformando los canales de distribución en un activo indispensable para sus estrategias comerciales.

\section{- Efecto candado derivado de los paquetes tecnológicos}

La expansión de los paquetes tecnológicos con sus respectivas marcas registradas pasó a ejercer una barrera infranqueable de acceso en la etapa comercial. La semilla representa solo el primer paso de la implementación del paquete, a la que se adicionan otros complementos, como inoculantes, fungicidas y promotores de crecimiento 
de la misma marca; por lo tanto, la difusión de los insumos complementarios específicos genera nuevas barreras.

\section{- Financiamiento a productores}

Por último, la financiación a productores fue la herramienta que permitió completar el esquema de inserción de estas empresas en la producción agraria. Las empresas multinacionales, como proveedores de insumos, otorgan financiamiento asociado con las futuras cosechas a los productores para adquirir sus propios paquetes tecnológicos. Disponen de diversas herramientas financieras, ya sea a través de tarjetas bancarias agropecuarias o con financiamiento propio. La capacidad económica de financiar capital de trabajo se transforma en un elemento estratégico de su propuesta comercial.

\section{Conclusiones}

La creciente atomización de los procesos productivos, deslocalizados territorialmente pero estrechamente interconectados, obliga a pensar en modelos económicos que contribuyan a comprender dicho fenómeno, a indagar sobre las relaciones que se suceden entre los actores que participan de las diversas actividades y el porqué de dicha fragmentación y localización. Al profundizar en estos aspectos se comienzan a identificar las motivaciones que dan origen a la fragmentación productiva, así como los aspectos ineludibles para su adecuada coordinación. En esta dirección, el modelo de cadenas globales de valor echa luz sobre cómo la radicación de diversas actividades en distintos puntos del globo maximiza los beneficios económicos, al igual que también ofrece diversos esquemas respecto de la coordinación entre los actores participantes. La segmentación internacional de los procesos productivos no se produce de manera azarosa, sino que responde principalmente a un patrón de reubicación de eslabones de producción a gran escala. Su localización en países periféricos conlleva la especialización de estos en actividades de baja complejidad y caracterizadas por la ausencia de innovación. En contraposición, se encuentran las actividades con mayor valor agregado, involucrando 


\section{I Santiago Calvo}

competencias clave intensivas en conocimientos como I+D, diseño, marketing, entre otras. Los principales actores de las CGV reservan para sí mismos, en sus casas matrices, aquellas actividades que presentan altas y dinámicas barreras de entrada, lo cual les garantiza un importante componente de la renta de la cadena.

La heterogeneidad en la distribución de los beneficios demuestra la obsolescente, o al menos parcial, visión de los organismos internacionales, los cuales patrocinan la participación de los países en desarrollo en las CGV como un beneficioso mecanismo de acceso a los mercados internacionales. La conformación de estos sistemas globales de producción, caracterizados por una dicotómica estructura de mercado entre sectores manufactureros de bajo valor agregado y reducidos grupos de grandes empresas que concentran las actividades intensivas en conocimiento, plantea importantes desafíos para los actores económicos de los países en desarrollo en materia de acceso hacia actividades más rentables.

La gobernanza, derivada de la articulación de funciones entre los actores de la cadena, crea estructuras de gobierno con capacidad de tomar decisiones a lo largo de esta. Estas relaciones reflejan la asimétrica distribución de poder entre sus participantes e influye decisivamente en el upgrading de empresas locales. El proceso ascendente en la cadena de valor es determinado por un alejamiento de las actividades con bajas barreras de entrada en las que la competitividad reside esencialmente en los costos de producción. Un reposicionamiento hacia aquellas actividades donde los intangibles representen un factor de competitividad contribuiría a un mayor desarrollo local a largo plazo. Esta situación lleva a que la sobrevivencia y la competitividad de las empresas locales dependan de nuevos conocimientos y de su incorporación en las prácticas productivas, de manera que les permitan incrementar sus rentas y sostenerlas en el tiempo, alcanzando actividades con barreras de entrada duraderas. 
En palabras de Sztulwark y Juncal (2014, p. 129):

La integración global de la producción supone una redefinición en la naturaleza de las asimetrías en la economía mundial. En esencia, lo central radica en el proceso histórico de elevación de las barreras a la entrada en las actividades de innovación y de caída en las de producción. Este fenómeno se verifica simultáneamente con una diferenciación estructural de los sistemas de innovación sobre los que se construyen las capacidades competitivas de cada territorio. Por consiguiente, el concepto de cadena global de valor debe entenderse no sólo como herramienta conceptual para el diseño de políticas de desarrollo productivo, sino también a partir de su rol en el establecimiento y reproducción de jerarquías entre territorios que evidencian capacidades de innovación asimétricas. La dispersión de las actividades que componen las cadenas queda sujeta, en última instancia, a diferentes formas de coordinación, regulación y gobierno.

Por su parte, el nuevo paradigma agrícola dio paso a un crecimiento exponencial de la moderna biotecnología y al nacimiento de una industria global. El sector se consolidó de la mano de fusiones y adquisiciones empresariales, así como también de centros de $\mathrm{I}+\mathrm{D}$ especializados, convergiendo en grandes multinacionales que se posicionaron como proveedoras líderes de los genes que van a ser incorporados en las semillas. Así mismo, debieron articularse con los actores vernáculos que controlaban las variedades de semillas locales para su adaptabilidad a las condiciones climáticas y morfológicas del suelo. La conjunción de estas dos actividades derivó en una manifiesta división internacional del trabajo: mientras las empresas transnacionales se concentraron en las actividades intensivas en I+D de manipulación genética, los actores locales se dedicaron a la incorporación de esa tecnología en producción de semillas GM, a partir del control de las variedades y otros activos complementarios necesarios. En consecuencia, el sector reproducía las asimetrías de la economía mundial planteadas por Sztulwark y Juncal, reforzando las barreras de entrada en las actividades de innovación a través de diferentes y evolutivas barreras, mientras que las actividades de producción que 


\section{I Santiago Calvo}

se realizaban en cada territorio dependían de los desarrollos genéticos extranjeros.

Esta situación, junto con las implicancias que surgen del modelo de CGV, abonó la hipótesis del presente trabajo. Planteó que las restricciones que enfrentaba Argentina para participar en eslabones de alto valor agregado de la cadena de agrobiotecnología en semillas se derivaban, principalmente, de las barreras de entrada provenientes de la estructura de gobierno de la CGV. En primera instancia, se presentó como indispensable identificar las capacidades locales para desarrollar acciones intensivas en $\mathrm{I}+\mathrm{D}$ que requerían dichos eslabones. A partir del análisis del sistema sectorial de innovación, se pudo concluir la presencia de precondiciones institucionales relativamente favorables para la creación de redes que potencien la innovación en los eslabones situados aguas arriba de la cadena. El escenario institucional, tanto público como privado, se presenta como favorable para avanzar hacia actividades que hoy se localizan concentradas en un cada vez más reducido número de empresas trasnacionales. Para asegurar el proceso integral de $\mathrm{I}+\mathrm{D}+\mathrm{i}$ se debe fomentar no solo el pasaje de la idea al laboratorio, sino también el escalado de los desarrollos al nivel de planta de producción. A pesar de disponer de capacidades endógenas para el desarrollo y el mejoramiento de semillas, este último proceso manifiesta una escasa importancia dentro del sistema científico y tecnológico nacional, dificultando, por ende, las actividades de transferencia tecnológica.

Si bien la superación de las barreras de conocimiento es consecuencia de la evolución del sistema sectorial de innovación y su mayor vinculación con el sector privado local, a través del estudio de la CGV del sector, se pudieron identificar otras restricciones para competir en los eslabones iniciales de la cadena. Los recursos económicos de las empresas multinacionales les permitieron maximizar los beneficios procedentes de la protección intelectual de sus desarrollos, creando barreras de ingreso dinámicas que les aseguran el acceso a una significativa porción de la renta tecnológica. Esta condición necesaria, pero no suficiente, se complementó con la creación de canales directos 
de comercialización de sus productos y el financiamiento a los productores locales para la adquisición de sus paquetes tecnológicos.

La gobernanza de la CGV en agrobiotecnología ha ido mutando con los años con una ostensible tendencia hacia una mayor asimetría de poder entre sus actores. A su vez, estas estructuras de gobierno han desplegado crecientes y progresivas restricciones que suponen una dependencia de las empresas locales e inhiben los procesos de mejora de los actores locales. Dadas estas desiguales relaciones, las oportunidades para los actores locales de ascender en la cadena de valor son limitadas. Acorde con la literatura especializada, bajo estos esquemas de gobierno, solo serían viables los procesos de upgrading de producto o de procesos. Sin embargo, las capacidades científicotécnicas del país posibilitan un upgrading funcional para avanzar en actividades concentradas en los países centrales. Bioceres no solo representa un manifiesto ejemplo de ello, sino que a su vez pone en evidencia que únicamente por medio del upgrading colaborativo se podrán superar tanto las barreras de entrada hacia actividades intensivas en conocimientos como así también aquellas que demandan mayores escalas económicas, legales y comerciales.

En la actualidad, la competitividad de un país está asociada no solo a su dotación de recursos y al tamaño de su mercado, sino también a un conjunto de esfuerzos tecnológicos públicos y privados. Es en este marco que los sistemas nacionales de innovación adquieren un destacado papel como actores de peso en las economías nacionales. En definitiva, el siglo XXI evidencia un proceso de valorización de los activos intangibles por sobre la producción de bienes físicos. La moderna biotecnología, signada por un fuerte componente de I+D, se presenta como uno de los pilares de esta progresiva integración entre la ciencia, la tecnología y el ámbito productivo. El impulso de este sector contribuirá a una mejor inserción internacional de Argentina, alcanzando la especialización productiva en uno de los sectores de mayor dinamismo de la economía mundial. 


\section{Referencias}

( 2 de octubre de 2016). Tres grandes empresas están a punto de controlar la mayoría de los suministros agrícolas del mundo. elDiario.es \& The Guardian. Recuperado de http://www.eldiario.es/theguardian/ alimentario-grandes-empresas-acaparen-semillas_0_564493892.html Anlló, G. (2016). Biotecnología argentina al año 2030: llave estratégica para un modelo de desarrollo tecno-productivo. Buenos Aires: Ministerio de Ciencia, Tecnología e Innovación Productiva. Recuperado de http://www. mincyt.gob.ar/estudios/biotecnologia-argentina-al-ano-2030-llaveestrategica-para-unmodelo-de-desarrollo-tecno-productivo-sintesisejecutiva-12530

ArgenBio. (2017). Glosario. Consejo Argentino para la Información y el Desarrollo de la Biotecnología. Recuperado de http:/ / www.argenbio. org/index.php?action $=$ glosario\&car $=\mathrm{f}$

Argentina. Ley 20247 de Semillas y Creaciones Fitogenéticas. Recuperado de http://servicios.infoleg.gob.ar/infolegInternet/anexos/30000-34999/34822/texact.htm

Argentina. Ley 24481 de Patentes de Invención y Modelos de Utilidad. Recuperado de http://servicios.infoleg.gob.ar/infolegInternet/anexos/35000-39999/35001/texact.htm

Bisang, R. (2008). El desarrollo agropecuario en las últimas décadas: ¿volver a creer? En B. Kosacoff (Ed.), Crisis, recuperación y nuevos dilemas. La economía argentina 2002-2007. Cepal.

Bisang, R., \& Varela, L. (2006). Capítulo 1. Biotecnología y desarrollo. Un modelo para armar en la Argentina. En Bisang y otros, Panorama internacional de la biotecnología en el sector agrario. Universidad Nacional de General Sarmiento-Editorial Prometeo.

Cepal. (2013). América Latina y el Caribe en las cadenas internacionales de valor. Recuperado de https://www.cepal.org/es/publicaciones/35879america-latina-caribe-cadenas-internacionales-valor

Coriat, B., Orsi, F., \& Weinstein, O. (2003). Does biotech reflect a new science-based innovation regime? Industry and Innovation, 10, 231-253.

Dalle, D., Fossati, V., \& Lavopa, F. (2013). Cadenas globales de valor y políticas de desarrollo: trazando los límites de las visiones liberales 
de inserción a la economía global. Revista Argentina de Economía Internacional, (2), -5-15. Recuperado de http://www.cei.gov.ar/es/revistaargentina-de-econom $\% \mathrm{C} 3 \% \mathrm{ADa}$-internacional- $\mathrm{n} \% \mathrm{C} 3 \% \mathrm{BAmero}-2$ Gereffi, G., Humphrey, J., Kaplinsky, R., \& Sturgeon, T. (2001). Globalisation, value chains and development. Sussex: Institute of Development Studies. Recuperado de http://www.ids.ac.uk/files/dmfile/gereffietal323.pdf Gereffi, G., Humphrey, J., \& Sturgeon, T. (2005). The governance of global value chains. Institute of Development Studies. Review of International Political Economy, 12(1), 78-108. Recuperado de http://www.fao.org/ fileadmin/user_upload/fisheries/docs/GVC_Governance.pdf

Giuliani, E., Pietrobelli, C., \& Rabellotti, R. (2005). Upgrading in global value chains: lessons from Latin American clusters. World Development, 33(4), 549-573.

Gutman, G. (2012). Desarrollo de la agrobiotecnología en la Argentina. Nuevas tecnologías, renovadas problemáticas. Voces en el Fénix, sumario 12. Recuperado de http://www.vocesenelfenix.com/

Gutman, G., \& Lavarello, P. (2007). Biotecnología y desarrollo. Avances de la agrobiotecnología en Argentina y Brasil. Economía: Teoría y Práctica, 27, 9-39.

Humphrey, J. (2005). Shaping value chains for development: global value chains in agribusiness. Sectoral Project Agricultural Trade. Trade and Investment Promotion. Recuperado de https://www.researchgate.net/publication/259999233_Shaping_Value_Chains_for_Development_Global_Value_Chains_in_Agribusiness

Humphrey, J., \& Schmitz, H. (2002). Developing country firms in the world economy: governance and upgrading in global value chains. INEF Report. Institut für Entwicklung und Frieden der Gerhard-Mercator-Universität Duisburg. Retrieved from http://inef.uni-due.de/page/documents/ Report61.pdf

Kaplinsky, R. (2000). Spreading the gains from globalisation. IDS Working Paper 110. Retrieved from https://www.ids.ac.uk/files/Wp110.pdf

Kaplinsky, R., \& Morris, M. (2001). A handbook for value chain research. Vol. 113. IDRC. Retrieved from https://www.researchgate.net/ publication/42791981_A_Handbook_for_Value_Chain_Research Kosacoff, B., López, A., \& Pedrazzoli, M. (2007). Comercio, inversión y fragmentación del mercado global: ¿está quedando atrás América Latina? Buenos 
Aires: Cepal. Recuperado de http://archivo.cepal.org/pdfs/2007/ S0700429.pdf

Kreimer, P. (2006). ¿Dependientes o integrados?: la ciencia latinoamericana y la nueva división internacional del trabajo. Revista Nómadas, (24), 199-212.

Lall, S., Albaladejo, M., \& Zhang, J. (2004). Mapping fragmentation: electronics and automobiles in East Asia and Latin America. Oxford Development Studies, 32(3), 407-432. Retrieved from https://www.researchgate. net/publication/24085732_Mapping_fragmentation_Electronics_ and_automobiles_in_East_Asia_and_Latin_America

Lengyel, M. (2013). La producción en red en Argentina y sus fundamentos institucionales. Buenos Aires: Centro Interdisciplinario de Estudios en Ciencia, Tecnología e Innovación. Recuperado de http://www.mincyt.gob. ar/estudios/la-produccion-en-red-en-argentina-y-sus-fundamentosinstitucionales-9425

Lengyel, M. (2016). El surgimiento de ecosistemas productivos de alta tecnologia en Argentina: evidencias, aprendizajes y el rol de las politicas públicas. CIPPEC.

López, A., Ramos, D., \& Torre, I. (2009). Las exportaciones de servicios de América Latina y su integración en las cadenas globales de valor. Santiago de Chile: Cepal. Recuperado de http://www.cepal.org/publicaciones/ xml/3/35963/docw37fin.pdf

López, A., \& Ramos, D. (2009). Capítulo III. Inversión extranjera directa y cadenas de valor en la industria. En La Argentina ante la nueva internacionalización de la producción. Crisis y oportunidades (pp. 141-215). Buenos Aires: PNUD-Cepal. Recuperado de http://docplayer.es/1929331Capitulo-iii-inversion-extranjera-directa-y-cadenas-de-valor-en-laindustria-y-servicios-andres-lopez-daniela-ramos.html

Luna, I. (2009). Pymes y cadenas de valor globales. Implicaciones para la política industrial en las economías en desarrollo. Análisis Económico, XXIV(57), 199-216. Recuperado de https://idus.us.es/bitstream/ handle $/ 11441 / 16482 /$ file_1.pdf?sequence $=1$

Mancini, M. (2016). Inserción en cadenas de valor globales y patrones de innovación de empresas de países en desarrollo: las pymes de Argentina. Economía: Teoría y Práctica, (45), 5-37.

Mentaberry, A. (2010). El inicio de operaciones de Indear: un nuevo actor en el campo de la agrobiotecnología en Argentina. Revista de la Bolsa de Comercio de Rosario, (1511), 52-57. Recuperado de http://www.bcr. 
com.ar/Secretara\%20de\%20Cultura/Revista\%20Institucional/2010/ Agosto\%202010/Ciencia\%20y\%20tecnolog\%C3\%ADa.pdf OCDE. (2012). Mapping global value chains. Retrieved from https://www.oecd. org/dac/aft/MappingGlobalValueChains_web_usb.pdf

OCDE. (2013). Interconnected economies. Benefiting from global value chains. Retrieved from https://www.oecd.org/sti/ind/interconnected-economiesGVCs-synthesis.pdf

OCDE. (2009). The bioeconomy to 2030: designing a policy agenda. Retrieved from https:/ / www.oecd.org/futures/long-termtechnologicalsocietalchallenges / 42837897.pdf

OMC. (2013). Supply chain perspectives and issues. Retrieved from https://www. wto.org/english/res_e/publications_e/aid4tradesupplychain13_e.htm Padilla Pérez, R. (2014). Fortalecimiento de las cadenas de valor como instrumento de la politica industrial. Metodología y experiencia de la Cepal en Centroamérica. Desarrollo económico. México: Comisión Económica para América Latina y el Caribe (Cepal). Recuperado de http://www.cepal.org/ es/publicaciones/36743-fortalecimiento-cadenas-valor-como-instrumento-la-politica-industrial

Pellegrini, P. (2013). Transgénicos. Ciencia, agricultura y controversias en la Argentina. Bernal: Universidad Nacional de Quilmes.

Pietrobelli, C., \& Rabellotti, R. (2006). Upgrading to compete global value chains, clusters, and SMEs in Latin America. Inter-American Development BankIDB Bookstore. Retrieved from www.iadb.org/pub

Porter, M. (1982). Estrategia competitiva: técnicas para el análisis de los sectores industriales y de la competencia. Grupo Editorial Patria. Segunda edición reformada 2015.

Romani, F., Codner, D., \& Pellegrini, P. (2016). Laboratorios de agrobiotecnología: niveles de decisión en trayectorias de transferencia tecnológica. Ciencia, Docencia y Tecnología, XXVII(52), 209-237.

Srinivasan, C. (2003). Concentration in ownership of plant variety rights: some implications for developing countries. Food Policy, 28(5-6), 519546. Retrieved from http://centaur.reading.ac.uk/9195/

Sturgeon, T. (2008). From commodity chains to value chains: interdisciplinary theory building in an age of globalization. Industrial Perfomance CenterMIT. Retrieved from https://ipc.mit.edu/sites/default/files/documents/08-001.pdf 


\section{I Santiago Calvo}

Sztulwark, S., \& Girard, M. (enero-marzo, 2017). El desarrollo de la agrobiotecnología en Argentina desde una perspectiva de cambio estructural. Yura: Relaciones Internacionales, (9), 52-70.

Sztulwark, S., \& Juncal, S. (2014). Innovación y producción en la industria manufacturera: estudio comparativo de cadenas globales. Journal of Technology Management \& Innovation, 9(4), pp. 119-131

The Global Value Chains Initiative. Retrieved from www.globalvaluechains.org

Trigo, E., \& Cap, E. (2006). Diez años de cultivos genéticamente modificados en la agricultura argentina. Buenos Aires: Consejo Argentino para la Información y el Desarrollo de la Biotecnología-ArgenBio.

UNCTAD. (2013). Global value chains and development: investment and value added trade in the global economy. Retrieved from https://unctad.org/en/PublicationsLibrary/diae2013d1_en.pdf 